\title{
APORTACIONES Y NOTAS SOBRE LA DIFUSIÓN DE LA ÉPICA ANIMALESCA EN MANUSCRITOS DE LA BATRACOMIOMAQUIA HASTA EL S. XVI
}

\author{
RAMÓN TORNÉ TEIXIDÓ \\ Universitat Oberta de Catalunya*
}

\begin{abstract}
Resumen
La difusión de la épica animalesca representada por la Batracomiomaquia se puede estudiar a partir de la proliferación de manuscritos en los que el poema aparece copiado junto a las fábulas esópicas y buena parte del corpus escolar al uso. Estos códices contienen ricos y variados escolios (algunos incluso en latín) que constituían una ayuda al lector no siempre avezado a la lengua griega. Los datos nos confirman la suposición de que el poema entraba en el canon de lectura del que se nutrían hombres cultos, literatos y personajes de la corte ya en el Prerrenacimiento. Fue a partir de ahí que nuestro poema reforzaría su significado político que había de perdurar dos siglos más.

PALABRAS ClAVE: Batracomiomaquia, manuscritos, tradición clásica, Prerrenacimiento, Alfonso de Palencia.
\end{abstract}

\section{Abstract}

The spreading of epic with animals represented by the Batrachomyomachia can be studied from the proliferation of manuscripts where the poem appears alongside Aesopic fables and much of the corpus at use in schools. These manuscripts also contain rich and assorted scholia (some of them in Latin) to help the reader not connoisseur of Ancient Greek. The data confirms us in the assumption that the poem was a part of the canon of readings for educated men, writers and members of the court in the PreRenaissance. It was from there that our poem would reinforce its political significance at least for two more centuries.

KEY WORDs: Batrachomyomachia, manuscripts, classical tradition, Pre-Renaissance, Alfonso de Palencia.

Desde las primeras noticias que tenemos del poema, la Batracomiomaquia (la batalla entre ranas y ratones) se atribuyó a la legendaria personalidad de Homero ya al poco tiempo de su composición ${ }^{1}$ y según referencia del poeta satírico Marcial. ${ }^{2}$ De

Recibido: 23-04-2016 / Aceptado: 16-07-2016

* Nuestro agradecimiento al Proyecto de investigación «Literaturas clásicas y literaturas hispánicas en la Baja Edad Media y el Renacimiento» (Ref. FFI2013-43663)

${ }^{1}$ Hoy por hoy, podemos afirmar que hay bastante unanimidad en la datación del poema, aceptándose la segunda mitad del s. I a.C. Véase al respecto: van HERWERDEN, H., «De Batrachomyomachia», en Mnemosyne, N.S. 10, 1882, p. 171; WACKERNAGEL, J., Sprachliche Untersuchungen zu Homer, vol. III, VANDENHOECK U. RupReCht, G., 1916 (reimpr. 1970), pp. 188-199; AhLBORN, H., Untersuchungen zur pseudohomerischen Batrachomyomachie, tesis doct., Gotinga 1959, pp. 78-84.

2 Los testimonios más antiguos son Marcial (Epigr. xIV, 183), Estacio (Silvae I, praef. ad Stellam) y la Vita falsamente atribuida a Plutarco (Vita Homeri I, 5, p. 24, 28-30. Wilam, p. 412 West). Cf. TonNÉ, R. «La 
hecho resulta innegable que la Batracomiomaquia llegó a gozar de gran fama no tanto en la Antigüedad sino sobre todo entre los siglos del IX al xvi. Desde siempre se ha presentado esta obra como una divertida parodia: la accidentada muerte de un ratón ahogado en medio del lago mientras era conducido por una rana que desencadena una guerra - «una batalla que dura un solo día», se nos dice en el v. 303 - entre ranas y ratones. Se trata, además, de una guerra que cuenta con todos los ingredientes de la épica: asambleas de guerreros, asambleas entre los dioses, una detallada descripción de las armas, discursos de los generales de cada ejército, descripción de muertes cruentas siguiendo el más genuino estilo formular homérico, amén de toda clase de ingredientes que despiertan en el lector una agradable sonrisa. ${ }^{3}$

Prácticamente todos los estudiosos vienen a coincidir en una idéntica constatación: a buen seguro fue gracias a la autoridad del nombre de Homero, como padre putativo del poema, que le sobrevino una fama y una posición nunca imaginados en la historia de la literatura. ${ }^{4}$ De hecho, como ya hemos visto en otro lugar, ${ }^{5}$ en la Batracomiomaquia se mezclan de forma exquisita el estilo épico con el género cómicosatírico, la fábula, la anécdota y el dramatismo de la novela de aventuras grecolatina, la adivinanza, el mimo alejandrino. Sin embargo todo ello tiene en su base un origen que se encuentra in nuce en el tema que narra, esto es, la fábula de la rana y el ratón (384 Perry = 302 Hausrath) recogida en la Vida de Esopo, un auténtico thesaurus de moral y de tradiciones populares griegas. ${ }^{6}$

En efecto, la primera parte de la Batracomiomaquia depende directamente de esta fábula conservada en la Vida de Esopo, la escenifica, la desarrolla y le confiere un «halo novelesco»: nos encontramos con un contexto campestre, hay dos personajes de raigambre noble que se presentan y desean sellar su amistad con un paseo por el lago que, por desgracia, acaba trágicamente, incluso con una maldición a los dioses por impiedad. Una impiedad que vendría a ser el epimitio de la fábula y que remonta,

Batracomiomaquia en Roma», en Á. Sánchez-Ostiz, J. B. Torres y R. Martínez (eds.), De Grecia a Roma y de Roma a Grecia: un camino de ida y vuelta, Pamplona, EUNSA, 2007, pp. 227-236.

3 Los ejemplos in toto se encuentran recogidos y comentados en los dos mejores trabajos sobre el poema: Ludwich, A., Die homerische Batrachomachia des Karers Pigres nebst Scholien und Paraphrase, herausgegeben und erläutert von A. L., Leipzig, Teubner, 1896, pp. 319-425; WÖLKE, H., Untersuchungen zur Batrachomyomachie, Meisenheim am Glan, Anton Hain, 1978.

4 Fusillo, M., «Omero» La battaglia delle rane e dei topi, Batrachomyomachia. Introduzione, premessa al testo, traduzione, commento di M. F., Milán, Guerini e associati, 1988, pp. 43-52.

5 ToRné, R., [Homer], La Batracomiomàquia, Barcelona, Publicacions Universitat de Barcelona, tesis doct. microf. (núm. 3719), 2000, pp. 14-22; TORNÉ, R., «Sobre la mixtura de géneros en la Batracomiomaquia», en Ianua Classicorum. Temas y formas del Mundo Clásico. Actas del XIII Congreso Español de Estudios Clásicos, J. de la Villa, P. Cañizares, E. Falque, J.F. González y J. Siles (eds.), vol. II, Madrid, SEEC, 2015, pp. 287-294.

6 Cuartero, F. J., «Notícia preliminar», en Isop, Faules, vol. II, Barcelona, Fundació Bernat Metge, 1989, pp. 89-107. 
como ya sabemos, a una moral muy tradicional, de corte aristocrático, a saber, que los dioses castigan al traidor. ${ }^{7}$ Es a partir de este momento de la historia, y por decirlo con Francisco Rodríguez Adrados, que la fábula se traspasa a la épica: ${ }^{8}$ en el momento en que el mundo heroico hace aparición, el relato derivará a una $\mu \alpha ́ x \eta$, una batalla cruenta, pero a la vez disparatadamente cómica, como lo son todos los nombres de los personajes que toman parte en ella.

Llegados a este punto nos podemos preguntar si la Batracomiomaquia interesaba - o hasta qué punto interesaba - a los lectores de los poemas homéricos. ¿Acaso en los códices manuscritos de los poemas homéricos también se copiaba la Batracomiomaquia? ¿Solía formar parte la Batracomiomaquia del grueso del corpus homericum? Tenemos que rendirnos a la evidencia: de los ciento dieciocho manuscritos que transmiten el poema, ${ }^{9}$ no llegan a la mitad los que incluyen la Batracomiomaquia al lado de las grandes epopeyas. $^{10}$

No queda fuera de lugar, pues, preguntarse a quién interesaba la Batracomiomaquia. ¿Quién copiaba el texto de Batracomiomaquia? ¿Para quién copiaba este texto? A decir verdad, el poema se encuentra en medio de otras obras de carácter escolar, en códices misceláneos. El propietario - o el usuario - de estos códices que incluyen la Batracomiomaquia solía ser un maestro o un estudiante, interesado en una especie de antología de la literatura griega: eran antologías de la literatura griega ad hoc para quienes se iniciaban en la lectura de textos griegos. Al lado de la Batracomiomaquia se copiaban algunas tragedias de Eurípides, comedias de Aristófanes, Idilios de Teócrito, los Apotegmas de los reyes de Plutarco, epítomes escolares de la Ilíada, las máximas de Focílides o de Teognis, algunos pasajes de Hesíodo, el tratado de métrica de Hefestión, los versos áureos pitagóricos y, naturalmente, también se incluyen las Fábulas esópicas. ${ }^{11}$

\footnotetext{
7 Las relaciones de esta fábula con la Batracomiomaquia ya fueron observadas por Martin Crusius en una obra que formó parte del Index: Turco-Graeciae libri octo, Basilea, Henricpetrus, 1584, p. 387. Según ANTON Wiecher (Aesop in Delphi, Meisenheim am Glan, Anton Hain, 1961, p. 10-11) esta fábula formaría parte de la Vita Aesopi, por lo menos desde mediados del s. v a.C.

8 Rodríguez AdRAdos, F., Historia de la fábula greco-latina. Introducción y de los orígenes a la edad helenística, vol. 1, Madrid, Universidad Complutense, 1979, p. 159.

9 Lista actualizada (subsanando errores y confusiones de editores anteriores) en ToRNÉ, R., [Homer], La Batracomiomaquia, ob. cit., pp. 250-256.

10 LudWich, ob. cit., pp. 40-52; AlLEN, T. W., Homeri opera, vol. v, Oxford, Clarendon Press, 1912 (reimpr. 1986), pp. 164-167; WÖLKE, ob. cit., p. 39; Càssola, F., Inni Omerici, Milán: Fondaziones Lorenzo Valla, 1975 (reimpr. 1994), pp. 593-597; ToRné, R., Estudi i col lació de vint manuscrits de la Batracomiomàquia, Madrid, Eds. Clásicas, 2006.

11 Así por ejemplo, un manuscrito del s. xv conservado en la Biblioteca Nacional de Madrid con el texto de la Batracomiomaquia acompaña el corpus de fábulas esópicas. Cf. ToRNé, R., «El matritense B.N. 3697: estudio del texto de la Batracomiomaquia», en Cuadernos de Filología Clásica. Estudios Griegos e Indoeuropeos, 11, 2001, pp. 279-285.
} 
Conviene añadir también que en tales códices suele haber muchas glosas y numerosos escolios. La gran mayoría de todos ellos se pueden datar entre los siglos XIII y XVI: son glosas escritas en griego demótico, algunas (muy pocas) en latín, ${ }^{12}$ son observaciones y notas de carácter escolar (sobre todo sinónimos, notas de gramática y de sintaxis, esto último para deshacer el hipérbaton y ordenar con facilidad los diferentes sintagmas de la oración). ${ }^{13}$ Todos estos escolios y glosas estaban destinadas al uso de alumnos o de maestros (este detalle no parece incompatible o excluyente) y es signo de un importante ámbito de difusión y de conocimiento. La Batracomiomaquia no tuvo que esperar a la imprenta para obtener la fama. Sin ir más lejos, sectores eclesiásticos de Bizancio citan expresiones, palabras, versos de la Batracomiomaquia: por ejemplo, Metodio, patriarca de Constantinopla, a finales del s. IX, menciona nombres del poema y Nicéforo Cartofílax se regodea en la Vida de Teófanes el confesor con términos y adjetivación procedentes de la Batracomiomaquia, utilizando hasta algunos hápax legómena. Lo mismo sucede con Ignacio Diácono, o con León el Filósofo - autor de un epigrama dirigido a un joven para que se haga imitador del Homero de la Batracomiomaquia -. El dato más chocante podría ser Aretas de Cesarea que escribe una carta al obispo de Side, en Panfilia, citando algunas «ranas heroicas» del poema y encargándole copiar el texto: pues bien, tenemos ese manuscrito, el Baroccianus 50, el más antiguo que conserva el poema, está adornado con glosas y contiene - cómo no - versos apócrifos. Al lado de Aretas podemos nombrar a Eustacio de Tesalónica y a Juan Tzetzes, que citan la Batracomiomaquia y la atribuyen a Homero: el primero en el prólogo a su comentario sobre la Ilíada, el segundo, en sus Alegorías homéricas. ${ }^{14}$

Como sea, la Batracomiomaquia estaba en la base de la educación y era un ejercicio frecuente en las escuelas invitar a los alumnos a dar cuenta de su preparación variando, amplificando o interpretando dicho texto. En este contexto nacerían las sucesivas, incontables e inclasificables reelaboraciones de pasajes enteros que hacen prácticamente imposible la reconstrucción del poema original. ${ }^{15}$ Otra hipótesis

\footnotetext{
${ }_{12}$ LuDwich, ob. cit., pp. 480-484 copia el Vindobonense 284 (s. XV) que ofrece al final del poema un listado de los nombres propios en griego y en latín.

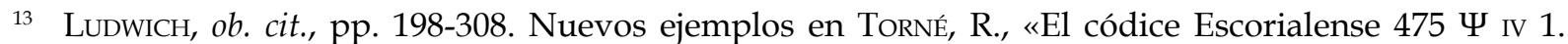
Estudio del texto y escolios de la Batracomiomaquia», en Fortunatae, 12, 2001, pp. 239-260; ToRNÉ, R.,

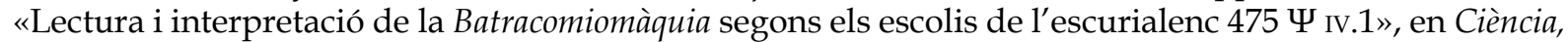
Didàctica i Funció Social dels Estudis Clàssics (Actes del XIV Simposi de la Secció Catalana de la SEEC), B. Usobiaga y P. J. Quetglas (eds.), Barcelona, PPU, 2004, pp. 389-394.

14 Los textos (y ediciones al uso) de estos testimonios se encuentran recogidos por ToRNÉ, R., [Homer], La Batracomiomaquia, ob. cit., pp. 97-127. El Barocc. 50 recoge un verso apócrifo que había pasado desapercibido a todos los editores, el v. 252b: cf. GLEI, R., Die Batrachomyomachie. Synoptische Edition und Kommentar, Fráncfort del Meno-Berna-Nueva York-Nancy, Peter Lang, 1984, pp. 60, 100, 196.
}

15 Son fehacientes las afirmaciones de Wölke al respecto: «No tengo conocimiento de ninguna otra obra de la Antigüedad que haya sufrido a lo largo de los siglos bizantinos un número tan cuantioso de interpolaciones» (ob. cit., p. 40). Por lo demás, véase DAIN, A., «À propos de l'étude des poètes anciens à 
que se ha apuntado es que la Batracomiomaquia, ya desde su génesis, era un poema ampliamente difundido por vía oral y, por ello mismo, estaba sometido continuamente a reelaboraciones, amplificaciones o mutilaciones según el gusto o las exigencias del momento. Los sucesivos añadidos, por tanto pueden ser debidos a los ejercicios escolares o a la difusión del poema en un ámbito cultural «popularizado». Ambas hipótesis no se contradicen, sino que se ayudan. ${ }^{16}$

Caterina Carpinato señaló en su día, y con gran acierto, la presencia de unas glosas interlineales en griego demótico, escritas a tinta roja en dos manuscritos del poema, en concreto el Parisino 2008 y el Véneto de la biblioteca Marciana Ix.14. ${ }^{17}$ Según pudimos comprobar, estas glosas son muy similares a las que se contienen en

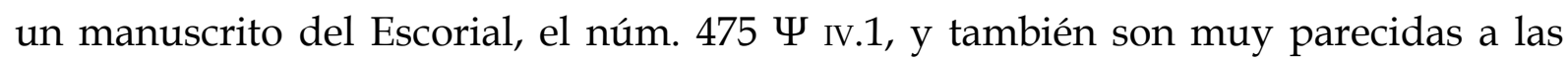
glosas y escolios impresos en tinta roja, cual si de un códice se tratara, en la edición de la Batracomiomaquia publicada en Venecia en 1486, a cargo de Laónico de Creta. Esta edición también incorpora la paráfrasis en griego bizantino de Teodoro de Gaza y la traducción al latín de Carlo Marsuppini. ${ }^{18}$ Dos años después, en 1488, se publicaría en Florencia una segunda edición del poema, esta vez formando parte de H toṽ O Oúpov поínoıs äпаба, también a cargo de otro griego, Demetrio Calcóndilas. No son trabajos fuera de contexto: Laónico de Creta era discípulo de Miguel Apostolio, autor de unos versos políticos sobre la Batracomiomaquia y contó con la ayuda de Demetrio Lucas y Marco Musuro. ${ }^{19}$ Estos dos humanistas también colaboraron en la imprenta de Aldo Manuzio, autor de la segunda versión de la Batracomiomaquia al latín. ${ }^{20}$ Esta última traducción seguramente debió de conocer López Pinciano, según se desprende de unos comentarios en su Philosophia antigua poética (1596). ${ }^{21}$ También la debió conocer Luis Zapata, autor de un poema heroico en honor de Carlos v, Carlo famoso, escrito en

Byzance», en Studi in onore di Ugo E. Paoli, Florencia, Le Monnier, 1956, pp. 195-201.

16 WÖLKE, H., ob. cit., p. 42.

17 CARPINATO, C., «La fortuna della Batrachomyomachia dal Ix al XVI secolo: da testo scolastico a testo politico», en «Omero» La battaglia delle rane e dei topi, ob. cit., pp. 142-143.

18 Marsuppini debió acabar su versión hacia el 1431, compuesta en hexámetros latinos. Hoy por hoy se contabilizan más de setenta manuscritos de este texto. Véase FABBRI, R., «Carlo Marsuppini e la sua versione latina della Batrachomyomachia pseudo-omerica», en Saggi di linguistica e di letteratura in memoria di Paolo Zolli, Borghello, Cortellazzo, y Padoan (eds.), Padova, Antenore, 1991, pp. 555-566. Posiblemente la editio princeps de esta primera traducción latina fuera también la del texto griego de la Batracomiomaquia, en una edición bilingüe, griego-latín: véase ToRNÉ, R., «La Batracomiomaquia en una edición de Brescia (ca. 1474)", en Kleos. Estemporaneo di studi e testi sulla fortuna dell'antico, 9, 2004, pp. 45-57.

19 Para un panorama general son útiles las páginas y la bibliografía que recoge E. Kumarianú, «Griegos bizantinos en la Venecia del siglo XV», en Cuadernos del CEMYR, 10, 2002, pp. 113-121.

20 Toffanin, G., «Omero e il Rinascimento Italiano», en Comparative Literature, 1, 1949, pp. 55-62.

${ }^{21}$ Véase Vián, A., «La Batracomiomaquia y el Crotalón: de la épica burlesca a la parodia de la historiografía», en 1616: Anuario de la Sociedad Española de Literatura General y Comparada, 4, 1981, pp. 145-162. 
1566. ${ }^{22}$ No queda tan claro, sin embargo, que el primer traductor de la Batracomiomaquia al castellano, Juan de la Cueva, solamente se sirviera de las versiones latinas ${ }^{23}$ para su trabajo, cuya datación se estima hacia 1580, entre el poema de Luis Zapata y la Philosophia del Pinciano.

No olvidemos en ningún momento la literatura castellana anterior a la invención de la imprenta. Ya sabemos que la Batracomiomaquia depende de una fábula esópica. Pues bien, en el Libro de Buen Amor también se aprecia la presencia de esta misma fábula en el «Ensiemplo del mur topo e de la rana» (vs. 407-414). ${ }^{24}$ No es difícil suponer que el códice que circulaba por las escuelas del momento tenía esta fábula y que también tuviera la Batracomiomaquia. ${ }^{25} \mathrm{Y}$ no tiene por qué extrañarnos que Juan de Mena, al traducir algunos pasajes de la Ilias Latina para la corte de Juan II, se entretenga en comentar que Homero también es autor de otra obra, la Bratachoniomachia [sic], y que «otras obras se le atribuyen, pero dúdase por muchas razones que Homero las hiziese». ${ }^{26}$ ¿Y qué decir de su sucesor en la corte, el humanista Alfonso de Palencia? Si atendemos a su cronología, lo encontramos en Italia, sirviendo al cardenal Besarión y estudiando humanidades con Jorge de Trebisonda hasta el año $1453 .{ }^{27}$ Cuando vuelve a la corte y en 1457, a poco de inventarse la imprenta, escribe en latín una

\footnotetext{
22 BALCELLS, J. M., «La Batracomiomaquia y la epopeya burlesca en la Edad de Oro», en Actas del IX Simposio de la Sociedad Española de Literatura General y Comparada, vol. II, Zaragoza, Universidad de Zaragoza, 1994, pp. 25-30; САCHO, R., «Luis Zapata y el poema heroico: historia, entretenimiento y parodia», en Criticón, 115, 2012, pp. 67-83.

${ }_{23}$ CEBRIÁN, J., «Juan de la Cueva, traductor de la Batracomiomaquia», en Revista de literatura, 47, 1985, pp. 23-40. Podemos señalar que la primera versión italiana corresponde a Aurelio Simmaco de Iacobiti, que vivió en la corte aragonesa de Nápoles y, más tarde, bajo la munificencia del príncipe de Tarento, Antonio del Balzo. La subscriptio métrica que concluye su traducción data de agosto de 1456 . Véase Marinucci, M., Batracomiomachia. Volgarizzamento del 1456 di Aurelio Simmaco de Iacobiti, Padova, Esedra Editrice, 2001. La segunda versión del poema al italiano corrió a cargo de Gorgio Summariva (1470), poco antes de publicarse la versión latina de Marsuppini (1474).
}

24 LeCOY, F., Recherches sur le Libro de buen amor de Juan Ruiz, (nueva edición actualizada por A.D. Deyermond), Londres, Gregg International, 1974; BigLieRI, A., «El exemplum medieval en el Libro de Buen Amor», en Revista de Filología Española, 70, 1990, pp. 119-132.

25 Además de los dos códices conservados en bibliotecas españolas con el poema citados en notas anteriores (n. 12 y 14) hemos estudiado dos manuscritos más, ambos procedentes de El Escorial (uno de ellos adornado con escolios y glosas). No puede parecer una rareza, pues, hablar de la difusión de la Batracomiomaquia por tierras hispánicas. Puede verse ToRNÉ, R., «El códice Escurialense 285 Y III.15: texto y escolios de la Batracomiomaquia», en Anuari de Filologia Universitat de Barcelona (Secció D: Studia Graeca et Latina), 10, vol. XXII, 2000, pp. 67-93; «El códice Escorialense 414 X Iv.19: estudio y colación del texto de la Batracomiomaquia», en Faventia, 24/2, 2002, pp. 25-32.

26 LidA, M. R., La tradición clásica en España, Barcelona, Ariel, 1975, pp. 132 y 382; López Férez, J. A., «Datos sobre la influencia de la épica griega en la literatura española», en La épica griega y su influencia en la literatura española, Madrid, Ediciones Clásicas, 1994, p. 370.

27 Real, C., «Apuntes sobre el humanista Alfonso de Palencia y su obra», en Revista de Filología de la Universidad de La Laguna, 17, 1999, pp. 657-670; Allés, S., «Alfonso de Palencia y el humanismo italiano», en Cuadernos de Filología Italiana, 19, 2012, pp. 107-130; ReaL, C., «Alfonso de Palencia», en Domínguez, J.F., Diccionario biográfico y bibliográfico del humanismo español, Madrid, Ediciones Clásicas, 2012, pp. 639-645. 
curiosa imitación de la Batracomiomaquia que más tarde, él mismo traduce a la lengua castellana: la Batalla campal que los lobos y los perros ovieron. ${ }^{28}$ Tengamos en cuenta que todavía tenían que pasar casi tres decenios hasta que viera la luz la edición príncipe de la Batracomiomaquia. Por lo tanto, Alfonso de Palencia debía esta idea, el tema, al humus cultural de tráfico de códices manuscritos que corría por Venecia, Florencia y Roma amén de la protección que otorgó Juan in a literatos destacados de su tiempo.

Como sea, a finales del siglo XII la lectura de Batracomiomaquia toma un nuevo rumbo: su significación y valor no se quedan únicamente en el plano estéticoeducativo, pues a partir de ahora el poema se tomará como punto de partida para una interpretación moralizante que, a veces, convive con relecturas de la historia política. Y es que la mudanza de las vivencias humanas parodiándolas con personajes animalescos era un recurso que muy bien podía poner de manifiesto los defectos humanos. Es así que el poema se convierte en un texto político desde que Teodoro Pródromo, poeta contemporáneo de los Comnenos, compusiera su Catomiomaquia (o guerra del gato contra los ratones), en la que el mundo animal ridiculiza sin compasión a los gobernantes ávidos de guerra y de poder. La obra de Alfonso de Palencia, fechada cuando todavía no se había publicado la Batracomiomaquia se inserta en esa línea que culminará, en el siglo siguiente, en personalidades como Melanchton quien, en su tratado De utilitate fabularum (1526) toma la Batracomiomaquia como ejemplo para aleccionarnos de las consecuencias nefastas de las guerras o, ya entrados el s. xvII, en el jesuita alemán Jakob Balde, muy crítico en su Batracomiomaquia (publicada por vez primera en Ingolstadt en 1637) con respecto a la Guerra de los Treinta años. ${ }^{29}$ Alfonso de Palencia narra una auténtica «batalla campal» entre lobos y perros que tiene lugar en un imaginario locus amoenus. Su obra es alegoría de corte humanístico (pace Rafael

\footnotetext{
28 El original en latín se ha perdido y las ediciones en castellano dependen de un incunable de 1490. Es modélica la edición con estudio preliminar de MARTín ROMERO, J. J., La batalla campal de los perros contra los lobos. Una fábula moral de Alfonso de Palencia, San Millán de la Cogolla, Cilengua, 2013. Excelente aproximación a cargo de PARDO, M., «La Batalla campal de los perros contra los lobos», Annexes des Cahiers d'études hispaniques médiévales, 17, 2006, pp. 237-259. Hay que señalar, sin embargo, que el estilo elevado parodiado en este tipo de obras en el caso de Palencia no ha sido del todo consumado (tal vez por sus aficiones de cronista): véase BALCELLS, J. M., "Alfonso de Palencia y la epopeya burlesca», en Actas del i congreso nacional de latín medieval, Pérez González (ed.), León, Universidad de León, 1995, p. 239-240. Según Robert Tate, Palencia leyó únicamente la versión latina de la Batracomiomaquia de Carlo Marsuppini: cf. TATE, R.B., «Political allegory in fifteenth-century Spain: a study of the Batalla campal de los perros contra los lobos by Alfonso de Palencia (1423-1492)», en Journal of Hispanic philology, 1/3, 1977, p. 177, n. 9.

29 Para Melanchton hemos utilizado la edición de Bretschneider, C. G., Philippi Melanchtonis opera quae supersunt omnia, vol. Ix, Halle-Braunschweig, Corpus Reformatorum, 1843, pp. 116-120. Hemos podido consultar (y citamos) según la edición de la Batracomiomaquia de Jakob Balde publicada en Colonia por J. Busaeus, del 1660: Poematum Tomus II complectens heroica carmina Ec. Balde la subtituló «Tuba Romana cantata, aevo nostro accomodata et in libros quinque distributa». En su prólogo (p. 59) pone la acusación de las guerras de su tiempo en primer plano: «Hoc et homines faciunt... Disce nomina, disce sensum.»
} 
Alemany) del tumultuoso momento político que vivió nuestro autor, una vez vuelto de Italia, utilizando un exemplum no escogido al azar. La situación vendría a describir los problemas tras la caída del condestable Álvaro de Luna, asesinado por la nobleza en tiempos de Juan II, y los conflictos del posterior gobierno de Enrique IV: el lobo Harpaleo (cf. ő $\rho п \alpha \xi$, ladrón) sucumbe ante los perros por hacer dejación del mando del ejército y muere por descuidar la disciplina militar.

Que la interpretación de Batracomiomaquia siguió abriéndose camino también por nuevas líneas y derroteros, es un hecho del todo evidente. En el siglo siguiente la épica burlesca tiene en el Culex pseudovirgiliano y en la Batracomiomaquia pseudohomérica dos puntales que influyeron notablemente en el Orlando furioso de Ariosto y en el Viaje del Parnaso de Cervantes, ${ }^{30}$ cristalizando al fin en la Gatomaquia de Lope de Vega.

\section{Bibliografía}

AhLBorN, M., Untersuchungen zur pseudo-homerischen Batrachomyomachie, tesis doct., Gotinga, 1959.

Allen, T. W., Homeri opera, vol. v, Oxford, Clarendon Press, 1912 (reimpr. 1986).

AllÉs, S., «Alfonso de Palencia y el humanismo italiano», en Cuadernos de Filología Italiana, 19, 2012, pp. 107-130.

BAlcells, J. M., «La Batracomiomaquia y la epopeya burlesca en la Edad de Oro», en Actas del IX Simposio de la Sociedad Española de Literatura General y Comparada, vol. II, Zaragoza, Universidad de Zaragoza, 1994, pp. 25-30.

, «Alfonso de Palencia y la epopeya burlesca», en Actas del i congreso nacional de latín medieval, M. Pérez González (ed.), León, Universidad de León, 1995, pp. 237-243.

, «Viaje del Parnaso y la serie épico-burlesca española», en Actas del XI Coloquio Internacional de la Asociación de Cervantistas, C. Park (ed.), Seúl, Universidad Hankuk de Estudios Extranjeros, 2005, pp. 549-556.

BALDE, J., Poematum Tomus II complectens heroica carmina Ec., Coloniae, Apud J. Busaeum, 1660.

Biglieri, A., «El exemplum medieval en el Libro de Buen Amor», en Revista de Filología Española, 70, 1990, pp. 119-132.

Bretschneider, C. G., Philippi Melanchtonis opera quae supersunt omnia, vol. Ix, HalleBraunschweig, Corpus Reformatorum, 1843.

30 Véase Balcells, J. M., «Viaje del Parnaso y la serie épico-burlesca española», en Actas del Xi Coloquio Internacional de la Asociación de Cervantistas, C. Park (ed.), Seúl, Universidad Hankuk de Estudios Extranjeros, 2005, pp. 549-556. 
CACHO, R., «Luis Zapata y el poema heroico: historia, entretenimiento y parodia», en Criticón, 115, 2012, pp. 67-83.

CARPINATO, C., «La fortuna della Batrachomyomachia dal IX al XVI secolo: da testo scolastico a testo politico», en FusILLO, M., «Omero» La battaglia delle rane e dei topi, Batrachomyomachia, Milán, Guerini e associati, 1988, pp. 137-148.

CÀssola, F., Inni Omerici, Milán: Fondaziones Lorenzo Valla, 1975 (reimpr. 1994).

CEBRIÁN, J., «Juan de la Cueva, traductor de la Batracomiomaquia», en Revista de literatura, 47, 1985, pp. 23-40.

Crusius, M., Turco-Graeciae libri octo, Basilea, Henricpetrus, 1584.

Cuartero, F. J., «Notícia preliminar», en Isop, Faules, vol. II, Barcelona, Fundació Bernat Metge, 1989, pp. 89-107.

DAIN, A., «À propos de l'étude des poètes anciens à Byzance», en Studi in onore di Ugo E. Paoli, Florencia, Le Monnier, 1956, pp. 195-201.

FABBRI, R., «Carlo Marsuppini e la sua versione latina della Batrachomyomachia pseudoomerica», en Saggi di linguistica e di letteratura in memoria di Paolo Zolli, G. Borghello, M. Cortellazzo y G. Padoan (eds.), Padova, Antenore, 1991, pp. 555566.

FusILlo, M., «Omero» La battaglia delle rane e dei topi, Batrachomyomachia. Introduzione, premessa al testo, traduzione, commento di M. F., Milán, Guerini e associati, 1988.

GLEI, R., Die Batrachomyomachie. Synoptische Edition und Kommentar, Fráncfort del MenoBerna-Nueva York-Nancy, Peter Lang, 1984.

HeRWERden, H. van, «De Batrachomyomachia», en Mnemosyne N.S. 10, 1882, pp. 163177.

KumARIANÚ, E., «Griegos bizantinos en la Venecia del siglo XV», en Cuadernos del CEMYR, 10, 2002, pp. 113-121.

LeCoy, F., Recherches sur le Libro de buen amor de Juan Ruiz, A. D. Deyermond (ed.), Londres, Gregg International, 1974.

LÓPEz FÉREZ, J. A., «Datos sobre la influencia de la épica griega en la literatura española», en La épica griega y su influencia en la literatura española, Madrid, Ediciones Clásicas, 1994, pp. 359-409.

LidA, M. R., La tradición clásica en España, Barcelona, Ariel, 1975.

LuDwICH, A., Die homerische Batrachomachia des Karers Pigres nebst Scholien und Paraphrase, herausgegeben und erläutert von A. L., Leipzig, Teubner, 1896.

MarinucCI, M., Batracomiomachia. Volgarizzamento del 1456 di Aurelio Simmaco de Iacobiti, Padova, Esedra Editrice, 2001.

Martín Romero, J. J., La batalla campal de los perros contra los lobos. Una fábula moral de Alfonso de Palencia, San Millán de la Cogolla, Cilengua, 2013. 
PArdo, M., «La Batalla campal de los perros contra los lobos», en Annexes des Cahiers d'études hispaniques médiévales, 17, 2006, pp. 237-259.

Real, C., «Apuntes sobre el humanista Alfonso de Palencia y su obra», en Revista de Filología de la Universidad de La Laguna, 17, 1999, pp. 657-670. , «Alfonso de Palencia», en Domínguez, J.F., Diccionario biográfico y bibliográfico del humanismo español, Madrid, Eds. Clásicas, 2012, pp. 639-645.

Rodríguez Adrados, F., Historia de la fábula greco-latina. Vol. I: Introducción y de los orígenes a la edad helenística. Madrid, Universidad Complutense, 1979.

TATE, R. B., «Political allegory in fifteenth-century Spain: a study of the Batalla campal de los perros contra los lobos by Alfonso de Palencia (1423-1492)», en Journal of Hispanic philology, 1/3, 1977, pp. 169-186.

Toffanin, G., «Omero e il Rinascimento Italiano», en Comparative Literature, 1, 1949, pp. $55-62$.

TORNÉ, R., [Homer], La Batracomiomàquia, Barcelona, Publicacions Universitat de Barcelona, tesis doct. microf., núm. 3719, 2000.

«El códice Escurialense 285 Y III.15: texto y escolios de la Batracomiomaquia», en Anuari de Filologia Universitat de Barcelona (Secció D: Studia Graeca et Latina), 10, vol. xxII, 2000, pp. 67-93.

«El matritense B.N. 4697: estudio del texto de la Batracomiomaquia», en Cuadernos de Filología Clásica. Estudios Griegos e Indoeuropeos, 11, 2001, pp. 279285.

«El códice Escorialense $475 \Psi$ IV 1. Estudio del texto y escolios de la Batracomiomaquia», en Fortunatae, 12, 2001, pp. 239-260.

, «El códice Escorialense 414 X IV.19: estudio y colación del texto de la Batracomiomaquia», en Faventia, 24/2, 2002, pp. 25-32.

«Lectura i interpretació de la Batracomiomàquia segons els escolis de l'escurialenc $475 \Psi$ Iv.1», en Ciència, Didàctica i Funció Social dels Estudis Clàssics (Actes del XIV Simposi de la Secció Catalana de la SEEC), B. Usobiaga y P. J. Quetglas (eds.), Barce006Cona, PPU, 2004, pp. 389-394.

«La Batracomiomaquia en una edición de Brescia (ca. 1474)», en Kleos. Estemporaneo di studi e testi sulla fortuna dell'antico, 9, 2004, pp. 45-57.

Estudi i col lació de vint manuscrits de la Batracomiomàquia, Madrid, Eds. Clásicas, 2006.

, «La Batracomiomaquia en Roma», en De Grecia a Roma y de Roma a Grecia: un camino de ida y vuelta, Á. Sánchez-Ostiz, J. B. Torres y R. Martínez (eds.), Pamplona, EUNSA, 2007, pp. 227-236.

, «Sobre la mixtura de géneros en la Batracomiomaquia», en Ianua Classicorum. Temas y formas del Mundo Clásico. Actas del XIII Congreso Español de Estudios Clásicos, 
La épica animalesca en manuscritos de la Batracomiomaquia

J. de la Villa, P. Cañizares, E. Falque, J.F. González y J. Siles (eds.), vol. II, Madrid, SEEC, 2015, pp. 287-294.

VIÁn, A., «La Batracomiomaquia y el Crotalón: de la épica burlesca a la parodia de la historiografía», en 1616: Anuario de la Sociedad Española de Literatura General y Comparada, 4, 1981, pp. 145-162.

WaCKeRnagel, J., Sprachliche Untersuchungen zu Homer, vol. III, Gotinga, Vandenhoeck u. Ruprecht, 1916 (reimpr. 1970).

Wiecher, A., Aesop in Delphi, Meisenheim am Glan, Anton Hain, 1961.

WöLKE, H., Untersuchungen zur Batrachomyomachie, Meisenheim am Glan, Anton Hain, 1978. 